\title{
DEGORCE Alice (dir.), Chants funéraires des Mossi \\ (Burkina Faso)
}

Paris : Classiques Africains, 2014, 318p.

\section{Ludovic O. Kibora}

\section{(2) OpenEdition}

Journals

Édition électronique

URL : https://journals.openedition.org/clo/2414

DOI : $10.4000 /$ clo. 2414

ISSN : 2266-1816

Éditeur

INALCO

Édition imprimée

Date de publication : 31 décembre 2015

ISBN : 9782858312276

ISSN : 0396-891X

\section{Référence électronique}

Ludovic O. Kibora, « DEGORCE Alice (dir.), Chants funéraires des Mossi (Burkina Faso) », Cahiers de littérature orale [En ligne], 77-78 | 2015, mis en ligne le 10 mai 2016, consulté le 01 juillet 2021. URL : http:// journals.openedition.org/clo/2414; DOl : https://doi.org/10.4000/clo.2414

\section{(@) $(1) \Theta$}

Cahiers de littérature orale est mis à disposition selon les termes de la Licence Creative Commons Attribution - Pas d'Utilisation Commerciale 4.0 International. 


\section{DegorCe Alice (dir.), 2014, Chants funéraires des Mossi (Burkina Faso), Paris : Classiques Africains, 318 p.}

L'ouvrage est un corpus d'une quarantaine de chants funéraires recueillis entre 2003 et 2007 . Toutefois, l'auteure ne se contente pas de présenter un simple répertoire de ce genre de l'oralité, elle explique leur contexte de production. Ces chants s'inscrivent dans le rog-n-miki, terme qui vacille entre tradition et religion des pères chez les Moose (ou Mossi, moaaga) du Burkina Faso. Pour mieux les rendre, Alice Degorce a suivi un principe de collecte et de transcription approprié, ce qui leur permet de conserver toute leur originalité. Ces chants, qui mettent en scène différents acteurs de la vie, évoquent la mort selon diverses représentations locales. Mort amère, mort réconciliatrice, mort unificatrice des membres du lignage. Douleur des vivants, assurance d'une vie qui se poursuit dans l'autre monde, le chant funéraire donne des indications sur la cosmogonie du peuple de Kindi. L'ouvrage nous montre qui chante et pourquoi pendant les funérailles. L'auteure nous replonge ainsi dans les bases de l'oralité africaine qui veut qu'en «Afrique n'importe qui ne dise pas n'importe quoi à n'importe qui ». Toute prise de parole a son sens et obéit à des normes sociales. Si la parole est importante dans ces sociétés, la chanson l'est davantage, le chant pouvant à l'image des gompagdo (paroles « à coque ») des Moose revêtir des significations au-delà de leur expression apparente. Bien que les critères de sélection des chants n'aient pas été spécifiés, le corpus offert au lecteur donne une idée de la quintessence des chants funéraires du site de l'étude. C'est pourquoi les Chants funéraires des Mossi (Burkina Faso), édités à partir d'un travail de terrain effectué dans le CentreOuest du Burkina Faso dans le village de Kindi, sont une source inestimable d'informations sur le traitement des morts, mais aussi sur la vie sociale au sein de la communauté villageoise. En choisissant de travailler sur ce genre de l'oralité qui intervient comme moyen d'expression par excellence en période de deuil et de rites funéraires, l'auteure confirme le fait que les textes de l'oralité peuvent servir de porte d'entrée pour l'étude des faits sociaux, voire des sociétés africaines. L'ouvrage est issu d'une thèse de doctorat d'anthropologie soutenue en 2009 
intitulée «Saluer la souffrance » : représentations des défunts et réseaux de relations dans les rites et les chants funéraires des Moose de l'Ouest (Burkina Faso). Cette monographie montre comment le traitement de la mort en Afrique est éloquent à propos de l'expression des liens sociaux. En outre, il renseigne sur la philosophie existentielle des humains, sur leurs systèmes de représentation.

C'est aussi ce qui ressort de ce document de 318 pages qui, au-delà du simple recueil de chants est en fait une étude sur les rites et les pratiques de deuil au sein d'une communauté moaaga, à partir des vers chantés. Ces chants collectés lors des « funérailles dans la souffrance » et lors « de la sortie des funérailles » permettent de comprendre l'image du vivant, du mort et de l'ancêtre. En effet, ils retracent, d'une part les relations entre le défunt et les vivants et, d'autre part, celles entre les vivants eux-mêmes.

Dès l'entame de l'œuvre, l'auteure situe le contexte et les conditions d'énonciation des chants. Elle fait une présentation sociopolitique du milieu d'étude pour faciliter la compréhension du répertoire de chants qui va suivre. Ensuite, les chants funéraires permettent de revisiter l'histoire du village et des lignages concernés. Le lecteur comprend que l'accompagnement social de la mort, la célébration des funérailles, lorsqu'ils sont effectués dans le respect des rites traditionnels, varient selon le statut social et matrimonial, l'âge et le sexe du disparu. En outre, toute mort est interprétée et classée selon différentes catégories. Ainsi les morts violentes (par suicide, par accident, par morsure de serpent, etc.) sont désignées comme de «mauvaises morts ». Par contre, une mort jugée naturelle, quand le défunt laisse en héritage à la communauté une progéniture, est qualifiée de «bonne mort ». Tout cela peut conditionner l'organisation ou non de funérailles. Ceux-ci augmentent les occasions voire les moments d'expression des chants.

Une des particularités de Kindi est que la pratique du culte des Sukoomse (société de masques) concerne la plupart des lignages. Ces masques sont très actifs lors des funérailles et leur sortie ne peut se faire sans chant ni danse. Si les chants transcrits ne sont pas ceux qui accompagnent ces sorties de masques, ils y font régulièrement référence. D'où la richesse d'un tel recueil de chants, à travers lequel l'auteure met en relief les messages divers, véhiculés à l'occasion par le groupe. Ils sont relatifs à la souffrance causée par la mort, au statut ou au caractère du défunt et aux retrouvailles futures. Chants d'hommage, chants d'accompagnement dans l'autre monde afin de parfaire le processus «d'ancestralisation » du disparu, les chants sont aussi l'occasion d'interpeller les vivants sur divers aspects qui fondent la vie en société. Ils évoquent la solidarité, la sagesse, l'amour du prochain, le respect des liens de parenté, l'importance des relations matrimoniales, etc. 
Enregistrés la plupart du temps en contexte de deuil, il est arrivé que des vers de certains chants soient inaudibles après coup. Ce que l'auteure avoue en prenant soin de le mentionner à l'emplacement prévu. Cela confirme les conditions de collecte en situation réelle et n'altère en rien la richesse d'ensemble du corpus qui fait œuvre utile à la préservation d'un riche patrimoine culturel immatériel. La publication de ce recueil de chants funéraires, qui suit les modalités de transcription littérale puis littéraire (malgré la non prise en compte des tons), permet à ce genre de l'oralité de garder toute son expressivité originelle. Les notes explicatives qui précèdent les chants témoignent de la rigueur d'une recherche ethnographique exhaustive qui se fonde sur l'exploitation des textes de l'oralité.

En plus d'être un apport important à la littérature orale africaine, Chants funéraires des Mossi (Burkina Faso) rend service à l'anthropologue et l'historien qui souhaite travailler sur cette aire culturelle. Dans l'ensemble, le style simple et agréable de l'œuvre la rend accessible à un public autre que celui du milieu académique.

Ludovic O. KiborA 